\title{
Coronary artery bypass grafting with a minimized cardiopulmonary bypass circuit: A prospective, randomized trial
}

\author{
Marc P. Sakwa, MD, ${ }^{a}$ Robert W. Emery, MD, ${ }^{b}$ Francis L. Shannon, MD, ${ }^{a}$ Jeffrey M. Altshuler, MD, ${ }^{a}$ Dawn Mitchell, RN, ${ }^{a}$ \\ Dan Zwada, CCP, ${ }^{\mathrm{a}}$ and Arlen R. Holter, $\mathrm{MD}^{\mathrm{b}}$
}

Objective: The study was designed to determine differences in blood loss and transfusion associated with a min-
imized cardiopulmonary bypass circuit versus a standard bypass circuit.

\begin{abstract}
Methods: From February 2005 through April 2006, 199 patients were randomized to undergo coronary artery bypass grafting with a standard cardiopulmonary bypass circuit (Medtronic, Inc., Minneapolis, Minn) or a minimized bypass circuit, the Medtronic Resting Heart Circuit. Laboratory perimeters (hemoglobin and platelet count), were measured at baseline, after initiation of cardiopulmonary bypass, and on intensive care unit admission. Lowest values recorded were noted. Blood administration was controlled by study-specific protocol orders, (transfusion for hemoglobin $<8 \mathrm{mg} \%$ ). Patient demographic data were retrieved from the Society of Thoracic Surgeons database. Blood product administration was recorded during hospital admission, and chest tube drainage as total output collected from operating room to discontinuation. Continuous variables were tested with a Wilcoxin rank test, and categoric variables with $X^{2}$ and Fisher's exact tests.
\end{abstract}

Results: Hematocrit, equivalent at baseline, was higher in minimized circuit cohort at lowest point during cariopulmonary bypass $(31.5 \% \pm 3.9 \%$ vs. $25.5 \% \pm 3.7 \%)$, after protamine $(31.6 \% \pm 3.9 \%$ vs $29.2 \% \pm 3.7 \%)$, and on intensive care unit arrival $(35.2 \% \pm 4.1 \%$ vs $31.8 \% \pm 3.5 \%, P<.001)$. Similarly, platelet count was higher in minimized circuit group on intensive care unit arrival, as was lowest platelet count recorded $\left(170 \times 10^{3} \pm 48\right.$ cells $/ \mathrm{mm}^{3}$ vs $107 \times 10^{3} \pm 28$ cells $\left./ \mathrm{mm}^{3}, P<.0001\right)$. Time to extubation was shorter in minimized circuit group $(848 \pm 737$ minutes vs. $526 \pm 282$ minutes, $(P<.01)$, and total chest tube drainage was lower $(1124 \pm 647 \mathrm{~mL}$ vs. $506 \pm 214 \mathrm{~mL}, P<.01)$. Fewer red blood cells (148 vs 19 units) were given in minimized circuit group $(P<.0001)$.

Conclusions: A minimized cardiopulmonary bypass circuit provides less hemodilution, platelet consumption, chest tube output and lower post-operative blood loss than standard cardiopulmonary bypass. Red blood cell usage was also less. All differences are advantageous.

Since its introduction in the 1950s, cardiopulmonary bypass (CPB) has allowed the development of heart surgery, which has become the most common of surgical procedures performed on a global basis. ${ }^{1}$ Even though CPB has been used in millions of cases during the past 56 years, there are still unsolved problems, many of which have been elucidated in the past decade. These problems include but are not limited to hemodilution, complement and white cell activation with systemic inflammatory response, platelet activation, the need for intensive anticoagulation, systemic organ dysfunction, and the frequent need for blood and blood products to control postbypass bleeding or blood loss. ${ }^{2-5}$ Atrial fibrillation (AF), the most common untoward event after heart surgery, has also been related to $\mathrm{CPB} .{ }^{6,7}$ To address

\footnotetext{
From the Division of Cardiovascular Surgery, William Beaumont Hospital, Royal Oaks, Mich, ${ }^{\text {a }}$ and the Division of Cardiovascular Surgery, St Joseph's Hospital, St Paul, Minn. ${ }^{\text {b }}$

Supported by an unrestricted grant from Medtronic Inc to the Beaumont Research Institute.

Received for publication April 17, 2008; revisions received Aug 4, 2008; accepted for publication Aug 27, 2008.

Address for reprints: Robert W. Emery, MD, 640 Jackson St, MS: 11503K, St Paul, MN 55101 (E-mail: robert.w.emery@healthpartners.com).

J Thorac Cardiovasc Surg 2009;137:481-5

$0022-5223 / \$ 36.00$

Copyright (C) 2009 by The American Association for Thoracic Surgery

doi:10.1016/j.jtcvs.2008.08.057
}

some of these concerns, surgeons initially began doing coronary artery bypass grafting $(\mathrm{CABG})$ procedures without the use of CPB (off-pump CABG, or OPCAB). ${ }^{7,8}$ During the 1990s, OPCAB became popular; because of the technical difficulties encountered in this procedure, however, as well as a questionable effect on long-term graft patency, OPCAB is currently performed in fewer of $25 \%$ of CABG procedures. ${ }^{9,10}$ A further means of combating the side effects of CPB has been the development of minimized circuits. ${ }^{6,11,12}$ These circuits minimize foreign surface-blood interaction and are heparinized from tip to tip. The tubing length has been shortened to decrease crystalloid prime. Importantly, the use of cardiotomy suction is eliminated or minimized, and an active air-removal device is added to this closed circuit. To evaluate the potential advantages of a minimized circuit relative to a standard $\mathrm{CPB}$ (SCPB) unit, a prospective, randomized trial was conducted.

\section{MATERIALS AND METHODS}

After investigation review board approval was received, 199 patients older than 40 years who were to undergo first-time CABG were randomly assigned to the use of a Medtronic Resting Heart (RHC) minimized circuit (Medtronic, Inc, Minneapolis, Minn) or a standard Medtronic CPB circuit (SCBP) at the time of surgical scheduling by means of computer-generated randomization cards sealed in envelopes. The study was conducted from February 2005 through April 2006. Exclusionary criteria included 


$$
\begin{aligned}
& \text { Abbreviations and Acronyms } \\
& \begin{aligned}
\mathrm{AF} & =\text { atrial fibrillation } \\
\mathrm{CABG} & =\text { coronary artery bypass grafting } \\
\mathrm{CPB} & =\text { cardiopulmonary bypass } \\
\mathrm{ICU} & =\text { intensive care unit } \\
\mathrm{MRH}= & \text { Medtronic Resting Heart minimized } \\
& \text { circuit } \\
\mathrm{OPCAB}= & \text { off-pump coronary artery bypass } \\
& \text { grafting } \\
\mathrm{RAP}= & \text { retrograde autologous priming } \\
\mathrm{RHC}= & \text { Resting Heart circuit } \\
\mathrm{SCPB}= & \text { standard cardiopulmonary bypass }
\end{aligned}
\end{aligned}
$$

coagulopathy (international normalized ratio $>2$ ), emergency surgery, and surgery expected to last longer than 6 hours. Additionally excluded were patients who received $11 \mathrm{~b} / 111 \mathrm{a}$ platelet inhibitors, clopidogrel, or thrombolytic therapy within 5 days of surgery; those who showed evidence of ventricular or aortic aneurysm or ventricular thrombus; and those who required other concomitant therapy. Aprotinin was not used.

Operating personnel could not be blinded to circuit randomization. Extubation was carried out by intensive care unit (ICU) intensivist staff according to the Beaumont Hospital protocol for all patients undergoing heart surgery. The ICU physicians were aware that the patients were in the CPB study, but did not know which circuit had been used. The study patients represented fewer than $20 \%$ of the heart operations conducted during the study period.

Transfusion of red blood cells was controlled intraoperatively and postoperative by a study-specific protocol to administer blood if hemoglobin fell below $8 \mathrm{mg} / \mathrm{dL}$ in both groups. There were no protocol violations.

Intraoperative fluids were limited by protocol, and perfusion pressure was maintained during retrograde autologous priming (RAP) by pressor administration. RAP was discontinued if patient hypotension related to hypovolemia occurred.

\section{Hematologic Parameters and Other Data}

Laboratory parameters recorded included hematocrit on entry to the operating room, after the administration of heparin, at its nadir during CPB, after protamine administration and, on arrival at the ICU. Platelet count was measured at baseline, on admission to the ICU, and as the lowest platelet count recorded during the hospital stay.

During the hospital stay, the total numbers of units of blood and blood products were recorded, and the timing of product administration was noted. Chest tube drainage was recorded as total output collected from the operating room drainage initiation to chest tube discontinuation, and extubation time was measured from arrival at the ICU until the endotracheal tube was removed.

Pertinent demographic data, operative data, and postoperative adverse events were retrieved from the Society of Thoracic Surgeons database collection.

\section{Circuit Description}

The RHC was selected for use after a large experience with routine heart surgery. A closed circuit (containing an active air-removal device) with a centrifugal pump and Carmeda-coated (Carmeda $\mathrm{AB}$, Upplands Väsby, Sweden) high-efficiency oxygenator forms the core of the system (Figure 1). The tubing consists of a $48 \times 0.375$-inch arterial line and $84 \times 0.375$-inch venous tubing, as opposed to the SCPB circuit, with tubings $80 \times 0.375$ inches and $120 \times 0.5$ inches, respectively, thus minimizing crystalloid priming volume to approximately $900 \mathrm{~mL}$ versus $1850 \mathrm{~mL}$. Because of the shorter tubing length, the circuit has to "nestle" closely to the patient, making the vertical array an important space-saving feature. The RHC is coated

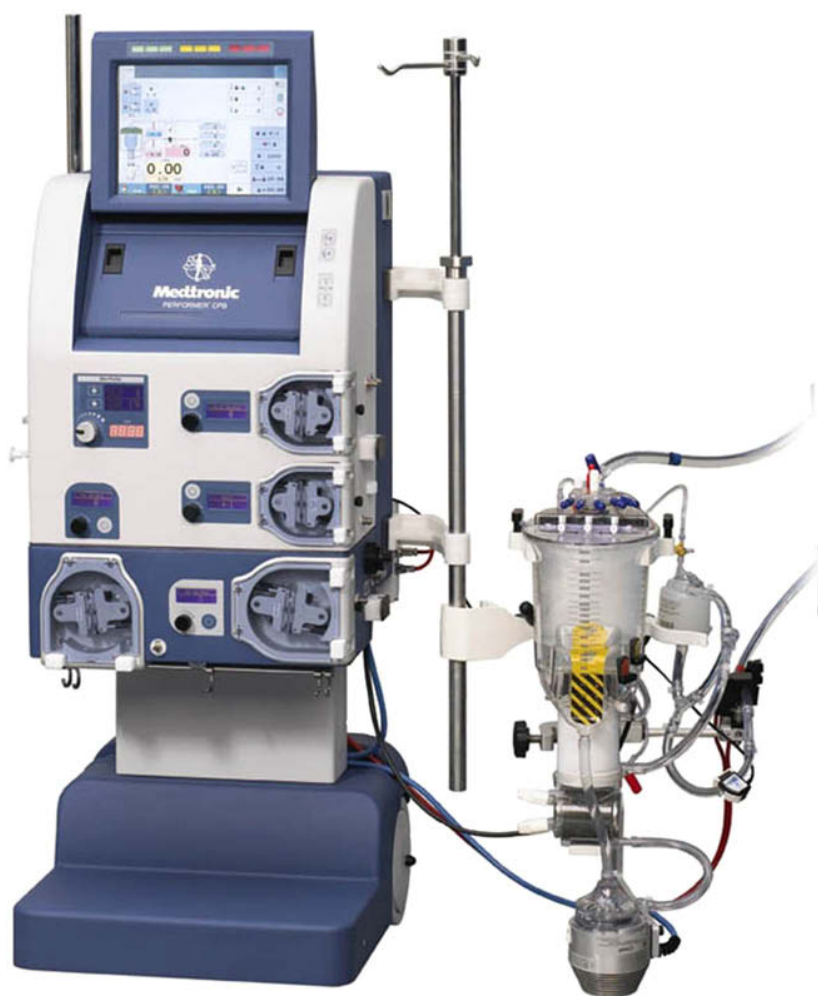

FIGURE 1. Medtronic Resting Heart circuit (Medtronic, Inc, Minneapolis, Minn) used in trial.

tip to tip with a Carmeda heparin surface. Our circuit included a Trilliumcoated (BioInteractions Ltd, Reading, UK) reservoir limited to aortic root vent return, thus rendering the circuit semiclosed. ${ }^{13}$

Heparin was administered (350 units/kg) to maintain activated clotting time greater than 400 seconds. Standard aortic and venous cannulations were undertaken, and in the RHC group kinetic assistance was used for venous drainage (40-50 $\mathrm{mm} \mathrm{Hg}$ suction). After cannulation, RAP was used to displace all but $300 \mathrm{~mL}$ of crystalloid prime in the RHC to a bag reservoir, which was separated from the circuit and reinfused to the circuit after CPB, displacing blood from the tubing. All salvaged cells were washed and reinfused. In contrast, the Medtronic SCPB circuit, as noted, used the same biopump and oxygenator but did not have an active air-removal system. The SCBP membrane oxygenator and reservoir were Trillium coated. RAP was also used in the SCBP cohort; because of patient hypotension, however, only about half of the $1850-\mathrm{mL}$ volume could be displaced.

\section{Patient Population}

There were 199 patients randomly allocated, 97 to SCPB and 102 to RHC. Mean age was $67 \pm 10$ years (range $39-86$ years). Demographic characteristics of the patients are shown in Table 1, and the operative procedures are shown in Table 2 . The left internal thoracic artery was used in all cases. Proximal and distal anastomoses were conducted under aortic crossclamp with the heart stilled by the administration of surgeon-specific cardioplegic solution. There was no 30-day mortality. One SCBP patient was returned to the operating room for surgical bleeding. One patient in each group required intraoperative balloon placement.

\section{Statistical Analysis}

Continuous variables were tested with a Wilcoxon rank test, a nonparametric approximation of the $t$ test. Categoric variables were examined with a $\chi^{2}$ test; otherwise, a Fisher exact test was used. Values are expressed as mean $\pm \mathrm{SD}$. 
TABLE 1. Demographic characteristics by circuit type

\begin{tabular}{lccr}
\hline & Standard & Minimized & Total \\
\hline Sex & & & \\
$\quad$ Male & $68(70 \%)$ & $74(73 \%)$ & $142(71 \%)$ \\
$\quad$ Female & $29(30 \%)$ & $28(27 \%)$ & $57(29 \%)$ \\
Age $(\mathrm{y})$ & & & \\
$\quad$ Mean \pm SD & $66.7 \pm 10$ & $67.4 \pm 10$ & \\
$\quad$ Range & $44-84$ & $39-86$ & \\
Height $(\mathrm{cm})$ & & & \\
$\quad$ Mean \pm SD & $172 \pm 8$ & $173 \pm 9$ & \\
$\quad$ Range & $152-188$ & $150-193$ & \\
Weight $(\mathrm{kg})$ & & & \\
$\quad$ Mean \pm SD & $84 \pm 16$ & $85 \pm 16$ & \\
$\quad$ Range & $50-122$ & $53-116$ & \\
Body surface area $\left(\mathrm{m}^{2}\right)$ & & & \\
$\quad$ Mean \pm SD & $1.96 \pm 0.2$ & $1.99 \pm 0.2$ & \\
$\quad$ Range & $1.53-2.5$ & $1.50-2.4$ & \\
\hline
\end{tabular}

$P$ not significant for all comparisons.

\section{RESULTS}

CPB times were similar between groups ( $76 \pm 20$ minutes for SCBP and $75 \pm 20$ minutes for RHC, $P>.05$ ). As shown in Table 3, the hematocrit was significantly higher at all times after the initiation of CPB with the RHC as opposed to the conventional circuit. Similarly, platelet count was higher in patients in whom the RHC was used at all times after baseline. The times to extubation were $848 \pm 737$ minutes in the SCBP group and $526 \pm 282$ minutes in the RHC group $(P<.01)$. Total chest tube drainage in the SCPB group (1124 $\pm 647 \mathrm{~mL})$ was greater than that in the RHC group $(560 \pm 214 \mathrm{~mL}(P<.001)$. In addition to the blood count being higher in patients in the RHC group, more patients in the SCBP group required the use of red blood cells, and a greater number of red cell units were given both on bypass and during the hospital stay in the SCBP group (Table 4). The use of platelets in the operating room ( 8 vs 3 patients) and in the ICU (4 vs 3 patients) was not statistically different $(P>.5)$ for SCBP versus RHC. Similarly, the use of fresh-frozen plasma was minimal, with a total of 5 units versus 1 unit for SCBP and RHC groups, respectively. Cell salvage reinfusion was not different between the RHC and SCBP groups $(716 \pm 256 \mathrm{~mL}$ and $810 \pm 346 \mathrm{~mL}$, $P>.05)$. Postoperative AF occurred in $16 \%$ of the patients, $14 \%$ in the RHC group and $19 \%$ in the SCBP group, with the difference not reaching significance. Cerebrovascular accidents were equally distributed, with 2 events in each group, and were all minor, requiring no therapy. There were no postoperative sternal wound complications.
TABLE 3. Hematologic parameters by circuit type

\begin{tabular}{lccc}
\hline & $\begin{array}{c}\text { Standard } \\
(\mathbf{n}=\mathbf{9 7})\end{array}$ & $\begin{array}{c}\text { Minimized } \\
(\mathbf{n = 1 0 2})\end{array}$ & $\boldsymbol{P}$ value \\
\hline Hematocrit $(\%)$ & & & \\
$\quad$ Baseline & $36.6 \% \pm 5.0 \%$ & $35.7 \% \pm 5.0 \%$ & .25 \\
After heparin & $35.3 \% \pm 5.0 \%$ & $34.2 \% \pm 4.8 \%$ & .09 \\
Lowest during CPB & $25.5 \% \pm 3.7 \%$ & $30.5 \% \pm 3.9 \%$ & $<.0001$ \\
After protamine & $29.2 \% \pm 3.7 \%$ & $31.6 \% \pm 3.9 \%$ & $<.0001$ \\
$\quad$ SICU & $31.8 \% \pm 3.5 \%$ & $35.2 \% \pm 4.1 \%$ & $<.0001$ \\
Platelets $\left(10^{3}\right.$ cells $\left./ \mathrm{mL}\right)$ & & & \\
$\quad$ Baseline & $218 \pm 55$ & $228 \pm 68$ & .49 \\
$\quad$ SICU & $117.4 \pm 31.1$ & $186.4 \pm 51.2$ & $<.0001$ \\
$\quad$ Lowest count & $106.9 \pm 28.5$ & $169.2 \pm 47.5$ & $<.0001$ \\
\hline $\begin{array}{l}\text { Data are mean } \pm \text { SD. CPB, Cardiopulmonary bypass; SICU, surgical intensive care } \\
\text { unit. }\end{array}$ & & &
\end{tabular}

\section{DISCUSSION}

Several models of minimized CPB circuits have been developed and used on a global basis, although as yet for a minority of patients. ${ }^{11,12,14-17}$ Remadi $^{13}$ has noted excellent exposure for complete revascularization and, in more than 1500 cases, found neither systemic injury nor occult air embolism, consistent with other reports. ${ }^{18-21}$ A minimized circuit has been used in all forms of heart surgery, including $\mathrm{CABG}$, aortic valve replacement, and robotically enabled mitral valve surgery. ${ }^{17,22,23}$ This randomized trial confirms previous non-American studies indicating that less blood administration is needed after minimized circuit use, with less blood loss during the immediate postoperative period. ${ }^{4,12,19,20}$ This is of particular importance because the administration of red blood cells can increase postoperative morbidity and mortality. ${ }^{24,25}$ Even after a successful surgical outcome, red blood cell transfusion has also been shown to reduce long-term survival. ${ }^{26}$ Thus it is important to eliminate transfusion.

The salutary effect of the minimized circuit is likely due to several factors. First, hemodilution is minimized by the shortened tubing length and the smaller inner diameter of tubing used, thus not only maintaining a higher hematocrit during the operative procedure and after $\mathrm{CPB}$ but minimizing the dilution of coagulation factors. Along with minimizing the blood-foreign surface interface, the shortened tubing with its tip-to-tip heparin coating also minimizes platelet activation. Because of the previously mentioned factor, less intensive anticoagulation is necessary during the $\mathrm{CPB}$ run, enabling better postoperative hemostasis. ${ }^{27}$ In our experience, approximately two thirds of the traditional heparinizing dose for the SCPB circuit is used. ${ }^{17}$ RAP is also an

TABLE 2. Number of grafts per procedure by circuit type

\begin{tabular}{lccccccc}
\hline \multicolumn{1}{c}{ Circuit } & CABGx1/Lima & CABGx2/Lima & CABGx3/Lima & CABGx4/Lima & CABGx5/Lima & Totals & Per Pt \\
\hline Conventional & 1 & 4 & 57 & 27 & 8 & 97 \\
MRHS & 0 & 7 & 45 & 38 & 11 & 101 \\
Totals & 1 & 11 & 102 & 65 & 3.38 \\
\hline
\end{tabular}


TABLE 4. Transfusions by circuit type

\begin{tabular}{lccc}
\hline & $\begin{array}{c}\text { Standard } \\
(\mathbf{n = 9 7 )}\end{array}$ & $\begin{array}{c}\text { Minimized } \\
(\mathbf{n = 1 0 2})\end{array}$ & $\boldsymbol{P}$ value \\
\hline Transfusion at any time (No.) & $49(51 \%)$ & $16(16 \%)$ & $<.0001$ \\
Total packed red blood cells (units) & 148 & 19 & $<.0001$ \\
Transfusion during bypass (No.) & $38(39.2 \%)$ & $7(6.9 \%)$ & $<.0001$ \\
\hline
\end{tabular}

important factor in red blood cell conservation and minimization of hemodilution; however, RAP was used in all cases in both groups, yet hemoglobin was higher and red blood cell use lower with the RHC at all times after the initiation of CPB. Thus RAP alone cannot explain all the salutary effects of the minimized circuit. Finally, because of the minimized closed circuit, the heparin coating, and, importantly, the decreased air-blood interface, the activation of white blood cells releasing inflammatory factors is minimized. Earlier extubation is likely related to less hemodilution and white blood cell activation, consequently resulting in less third-space edema. ${ }^{18}$

Immer and colleagues ${ }^{6}$ found improved myocardial protection in patients undergoing surgery with the minimized circuit as opposed to SCBP. In addition to improved protection, patients with the minimized circuit had less weight gain, and the authors believed these facts to be primarily responsible for the lower incidence of postoperative new-onset AF in their minimized circuit patients. Koch and coworkers ${ }^{28}$ found red blood cell transfusion to be associated with an increased risk of AF. We found no difference between groups in the incidence of AF. In patients at higher risk for AF, however, the impact of a minimized circuit may be more noticeable. Other reports have indicated that the minimized circuit offers similar decreases in all the previously mentioned parameters, which is more similar to OPCAB surgery than to SCBP; however, the use of RHC facilitates complete revascularization, especially for complex anatomy or unstable physiology not amenable to OPCAB. ${ }^{13,14,16}$

The systemic inflammatory response is the result of the activation of both cellular and humoral components. Although this study did not undertake the measurement of inflammatory markers, others have noted a decrease in the inflammatory response with minimized bypass circuits. $^{4,14,15,18,29}$ Inflammatory response activation may contribute to myocardial dysfunction, respiratory failure, renal insufficiency, confusion or stroke, and $\mathrm{AF}^{3,4}$ Eliminating or minimizing these effects is desirable.

A learning curve is necessary but is not associated with higher risk. ${ }^{13,19}$ There are three drawbacks to the minimized circuit that become apparent during its use. First, communication between the perfusion, anesthesiology, and surgical teams is more imperative than with SCBP. The blood pressure has to be maintained during RAP, and active communication when $\mathrm{CPB}$ is initiated is necessary to determine adequacy of perfusion because the circuit has been primed with the patient's blood.
Second, the effect of the minimal circuit volume and retrograde autologous priming may be obviated if too much crystalloid volume infusion is administered before and during the case. In this study, fluid was controlled by protocol, and perfusion pressure was maintained during RAP by pressor agent infusion.

Finally, because kinetic assistance is necessary, emptying of the heart with decreased perfusion flow can at times be difficult. One needs to ensure a complete seal around and proper positioning of the venous drainage cannulas to prevent air entering the circuit. and the surgeon must maintain active observation on the heart should the right atrium or right ventricle dilate with undrained volume, communicating with the perfusionist to improve drainage. ${ }^{19}$ There are specific instances - including the administration of cardioplegic solution, discontinuation of vent drainage, and, importantly, cardiac manipulation, particularly pulling the heart superiorly and to the right for access to the circumflex coronary artery system-that can impede venous drainage and lower perfusion flows. Drainage issues can also occur with vigorous traction on the left atrium during mitral valve surgery. Active communication among all portions of the surgical team is mandatory.

Air entry to the RHC was not encountered. The active airremoval system cleared any air that might enter the venous cannula and obviated, even eliminated, the occult air embolization that has been seen with SCBP. ${ }^{19}$

In summary, the RHC offers a viable alternative to the SCPB circuit. It has been associated with less postoperative blood loss, lower transfusion rates, and earlier extubation, while allowing adequate exposure for cardiac surgical procedures. This was a series of low-risk CABG surgical patients, and those in populations at higher risk may achieve greater benefit.

We acknowledge the work of Nicholas A. Tepe, MD, Phillip L. Robinson, MD, Joseph S. Bassett, MD, Goya V. Raikar, MD, Mark Pica, RN, and Joan Benedetti, RN, without whose efforts the project would be incomplete.

\section{References}

1. Gibbon JH Jr. Application of a mechanical heart and lung apparatus to cardiac surgery. In: Gibbon JH Jr, ed. Recent advances in cardiovascular physiology and surgery. Minneapolis: University of Minnesota; 1953. p. 107-13.

2. Butler J, Recker GM, Westaby S. Inflammatory response to cardiopulmonary bypass. Ann Thorac Surg. 1993;55:552-9.

3. Fromes Y, Gaillard D, Ponzio O, Chauffert M, Gerhardt MF, Deleuze P, et al. Reduction of the inflammatory response following coronary artery bypass grafting with total minimal extracorporeal circulation. Eur J Cardiothorac Surg. 2002;22:527-33.

4. Abdel-Rahman U, Ozaslan F, Ristesk P, Martens S, Moritz A, Al Daraghmeh A, et al. Initial experience with a minimized extracorporeal bypass system: is there clinical benefit? Ann Thorac Surg. 2005;80:238-43.

5. Levy JH, Tanaka KA. Inflammatory response to cardiopulmonary bypass. Ann Thorac Surg. 2003;75:5715-20.

6. Immer FF, Pirovino C, Gygax E, Englberger L, Tevaearai H, Carrel TP. Minimal versus conventional cardiopulmonary bypass: assessment of intraoperative myocardial damage in coronary bypass surgery. Eur J Cardiothorac Surg. 2005;28:701-4.

7. Edgerton JR, Herbert MA, Prince SL, Horswell JL. Reduced atrial fibrillation in patients immediately extubated after off-pump coronary artery bypass grafting. Ann Thorac Surg. 2006;81:2121-7. 
8. Puskas J, Cheng D, Knight J, Angelini G, DeCannier A, Dullum M, et al. Off-pump versus conventional coronary bypass grafting: a meta-analysis and consensus statement from the 2004 ISMICS Consensus Conference. Innovations. 2005;1:3-27.

9. Puskas JD, Steele M. Would you like some cardiopulmonary bypass with your coronary revascularization? Circulation. 2007;116:1756-8.

10. Gundry SR, Romano MA, Shattuck OH, Razzouk AJ, Bailey LL. Seven-year follow-up of coronary artery bypasses performed with and without cardiopulmonary bypass. J Thorac Cardiovasc Surg. 1998;115:1273-8.

11. Wiesenack C, Liebolo A, Philipp A, Ritzka M, Koppenberg J, Birnbaum DE, et al. Four years' experience with a miniaturized extracorporeal circulation system and its influence on clinical outcome. Artif Organs. 2004;28:1082-8.

12. Remadi JP, Marticho P, Butoi I, Rakotoarivelo Z, Trojette F, Benamar A, et al. Clinical experience with the mini-extracorporeal circulation system: an evolution or a revolution? Ann Thorac Surg. 2004;77:2172-6.

13. Remadi JP. Invited commentary. Ann Thorac Surg. 2008;85:1000-1.

14. Ascione R, Lloyd CT, Underwood MJ, Lotto AA, Pitsis AA, Angelini GD. Inflammatory response after coronary revascularization with or without cardiopulmonary bypass. Ann Thorac Surg. 2000;69:1198-204.

15. Beghi C, Nicolini F, Agostinelli A, Borrello B, Budillon AM, Bacciottini F, et al. Mini-cardiopulmonary bypass system: results of a prospective randomized trial. Ann Thorac Surg. 2006;81:1396-400.

16. Mazzei V, Nasso G, Salamone G, Castorino F, Tommasini A, Anselmi A. Prospective randomized comparison of coronary bypass grafting with minimal extracorporeal circulation system (MECC) versus off-pump coronary surgery. Circulation. 2007;116:1761-7.

17. Emery RW, Raikar GV, Murphy BJ, Rohan A, Nielsen K. The use of the mini-cardiopulmonary bypass circuit in robotic mitral valve surgery. Innovations. 2008;3:16-8.

18. Immer FF, Ackerman A, Gygax E, Stalder M, Englberger L, Eckstein FS, et al. Minimal extracorporeal circulation is a promising technique for coronary bypass grafting. Ann Thorac Surg. 2007;84:1515-21.

19. Ti LK, Goh BL, Wong PS, Ong P, Goh SG, Lee CN. Comparison of mini-cardiopulmonary bypass system with air-purge device to conventional bypass system. Ann Thorac Surg. 2008;85:994-1000.
20. Øvrum E, Holen EÅ, Tangen G, Brosstad F, Abdelnoor M, Ringdal ML, et al. Completely heparinized cardiopulmonary bypass and reduced systemic heparin: clinical and hemostatic effects. Ann Thorac Surg. 1995;60:365-71.

21. Perthel M, El-Ayoubi L, Bendisch A, Laas J, Gerigk M. Clinical advantages of using mini-bypass systems in terms of blood product use, postoperative bleeding and air entrainment: an in vivo clinical perspective. Eur J Cardiothorac Surg. 2007;31:1070-5.

22. Castiglioni A, Verzini A, Pappalardo F, Colangelo N, Torracca L, Zangrillo A et al. Minimally invasive closed circuit versus standard extracorporeal circulation for aortic valve replacement. Ann Thorac Surg. 2004;83:586-91.

23. Remadi JP, Rakotoarivello Z, Marticho P, Trojette F, Benamar A, Poulain H, et al Aortic valve replacement with the minimal extracorporeal circulation (Jostra MECC System) versus standard cardiopulmonary bypass: a randomized prospective trial. J Thorac Cardiovasc Surg. 2004;128:436-44.

24. Koch CG, Li L, Duncan AI, Mihaljevic T, Cosgrove DM, Loop FD, et al. Morbidity and mortality risk associated with red blood cell and blood-component transfusion in isolated coronary artery bypass grafting. Crit Care Med. 2006; 34:1608-16.

25. Koch CG, Li L, Sessler D, Figueroa P, Hoeltge GA, Mihaljevic T, et al. Duration of red cell storage and complications after cardiac surgery. N Engl J Med. 2008; 358:1229-39.

26. Koch CG, Li L, Duncan AI, Mihaljevic T, Loop FD, Starr NJ, et al. Transfusion in coronary artery bypass grafting is associated with reduced long-term survival. Ann Thorac Surg. 2006;81:1650-7.

27. Baufreton C, de Brux JL, Binuani P, Corbeau JJ, Subayi JB, Daniel JC, et al. A combined approach for improving cardiopulmonary bypass in coronary artery surgery: a pilot study. Perfusion. 2002;17:407-13.

28. Koch CG, Li L, Van Wagoner DR, Duncan AI, Gillinov AM, Blackstone EH. Red cell transfusion is associated with an increased risk for postoperative atrial fibrillation. Ann Thorac Surg. 2006;82:1747-56.

29. Just S, Müller T, Hartrumpf M, Albes JM. First experience with closed circuit centrifugal pump extracorporeal circulation: cellular trauma, coagulatory, and inflammatory response interact. Interact Cardiovasc Thorac Surg. 2006;5:646-8. 